\title{
Untrained versus specialized palaeontological systematics: A phylogenetic validity test using morphostructural conspicuity as character weight
}

\author{
David BUCKLEY* \& Borja SANCHIZ \\ Museo Nacional de Ciencias Naturales, MNCN-CSIC, J. Gutiérrez Abascal 2. Madrid 28006. Spain; dbuckley@mncn.csic.es \\ * Corresponding author
}

Buckley, D. \& Sanchiz, B. 2012. Untrained versus specialized paleontological systematics: A phylogenetic validity test using morphostructural conspicuity as character weight. [Sistemática paleontológica inexperta frente a especializada: un test de validez filogenética utilizando la perceptibilidad morfoestructural como pesaje de caracteres]. Spanish Journal of Palaeontology, 27 (2), 131-142.

\begin{abstract}
We performed a comparative osteological analysis of middle trunk vertebrae (represented by $\mathrm{V}_{6}$ ) of representative species of all living genera of Salamandridae (Amphibia, Caudata). The qualitative morphological characters used were adapted from the traditional palaeontological literature; using this data set we inferred a phylogenetic hypothesis for the family. The same morphological matrix was then re-analysed using a weighting scheme for the characters derived from the answers of a psychological test taken by an international group of graduate students unfamiliar with palaeoherpetology. We compared the phylogenetic results of both groups with the currently accepted evolutionary model for this family, which is based on mitochondrial and nuclear gene sequences. The ranking of the relative (and subjective) conspicuity of vertebral structural units (prezygapophyses, neurapophyses, etc.) collectively made by the inexpert group, presumably, directly derives from a general (human) capability to recognise shapes. The same perceptive pattern also seems to be involved in the character set developed by the specialists, and both matrices obtained similar results in the quality of their respective phylogenetic inferences. Defining characters is the most important step in systematics and, therefore, we
\end{abstract}

RESUMEN

Se realiza un análisis osteológico comparado de vértebras dorsales medias (representadas por $\mathrm{V}_{6}$ ) utilizando una especie representativa de cada género de Salamandridae (Amphibia, Caudata). Los caracteres morfológicos cualitativos seleccionados fueron adaptados de los que tradicionalmente se utilizan en paleontología y con ellos se infirieron los correspondientes modelos filogenéticos. La misma matriz morfológica se utilizó de nuevo, pero corregida mediante asignación de un pesaje diferencial a los caracteres, según los resultados de un test psicológico realizado por un grupo internacional de estudiantes de doctorado sin relación con la paleoherpetología. Los resultados filogenéticos de ambos grupos se compararon con el modelo evolutivo actualmente aceptado para esta familia, basado en secuencias de genes mitocondriales y nucleares. La ordenación por perceptibilidad relativa de cada unidad estructural de la vértebra (prezigapófisis, neurapófisis, etc.), realizada subjetivamente por el colectivo inexperto, puede suponerse que refleja la propia capacidad humana para el reconocimiento de formas. El mismo patrón perceptivo parece estar también presente en el conjunto de caracteres de los especialistas, y con ambas matrices se obtuvieron resultados similares en cuanto a la calidad de sus inferencias 
stress the importance of developing new tools and approaches for exploring new quantitative and qualitative characters in palaeontological research.

Keywords: Amphibia, Caudata, Salamandridae, osteology, phylogenetics, morphology.

\section{INTRODUCTION}

Taxonomy and systematics in vertebrate palaeontology rely on the study of either articulated or disassembled skeletons. However, the information obtained from the fossil record, especially from a disassembled skeleton, is usually fragmentary since fossilization, preservation, and thus prevalence, are uneven among anatomical parts. For instance, vertebrae are one of the most frequently found elements in fossil sites, and therefore, they have had a great impact on the taxonomy of some groups. This is the case of lissamphibians and, more specifically, of urodelan amphibians. Vertebrae in this group have played an important role in the description of extinct and extant fossil species. In fact, vertebrae are important elements in the type series of extinct urodele species (Martín \& Sanchiz, 2012). Among salamandrids, for instance, many fossils belong to living genera and species, although there are also some extinct taxa that differ morphologically from their living relatives (Estes, 1982; Milner, 2000). As a consequence, the same features used for the identification or discrimination among recent forms can also be directly applied to palaeontological studies.

Vertebrae are complex, segmental, and sequential elements. The morphology of the vertebrae not only varies along the vertebral axis of a single individual (e.g., vertebrae at the cervical, thoracic, or lumbar regions), but also intraspecifically and interspecifically. However, in spite of being considered as one of the most informative single elements, very few comparative neontological studies that could be potentially applied to palaeontological research have been published. Worthington \& Wake (1972), Naylor (1978), and Estes (1982), for instance, analysed the morphological variation in the different regions of the vertebral column as a taxonomic source of error. Teege (1957) summarized adult salamandrid comparative morphology from the point of view of development, whereas Haller-Probst \& Schleich (1994) provided a descriptive account of the adult vertebral morphology in living Eurasian salamandrids.

Despite the importance of this element in palaeobatrachology, the phylogenetic signal of the salamandrid vertebrae morphology has not been analysed, and vertebral morphological patterns have never been subjected to any standardization process. However, filogenéticas. Dada la importancia de la definición de caracteres para cualquier estudio sistemático e investigación paleontológica, enfatizamos aquí la necesidad de delimitarlos con nuevos métodos cuantitativos y cualitativos.

Palabras clave: Amphibia, Caudata, Salamandridae, osteología, filogenética, morfología. specialists working on salamandrid fossils have focused on similar features when selecting morphological characters in their studies. Defining taxonomic characters is a crucial first step in phylogenetic inference and, given the lack of standardization and analysis of phylogenetic signal in the salamandrid vertebrae morphology, we asked whether the characters, as defined by specialists in the field, are directly derived from the general capability to recognise variation in basic shapes, or if they have been transformed into different and more accurate inference tools. To provide a preliminary answer to this question, we compared the phylogenetic inferences generated through the analysis of three data sets: 1) A character matrix derived and weighted from a simple psychological test in which we asked graduate students unfamiliar with palaeoherpetology to select and define the characters, 2) a data matrix incorporating the characters traditionally used by expert palaeoherpetologists, and 3) a reference phylogeny based on mitochondrial and nuclear gene sequences, used as the evolutionary model for the family (Pyron \& Wiens, 2011). Our results, although provisional in the understanding of how morphological characters are defined, are not only restricted to salamandrid vertebrae as presented in this study; they could also be generalized to any other taxonomic character and group.

\section{MATERIALS AND METHODS}

\subsection{Comparative material}

We studied isolated vertebrae from dry skeletal preparations of representatives of all the currently accepted living salamandrid genera, with the exception of Laotriton, using as a taxonomic standard the database 'Amphibian Species of the World 5.5' (Frost, 2011). Unless otherwise stated, the characters described in this study are taken from the sixth vertebra $\left(\mathrm{V}_{6}\right)$ of all the specimens, being the atlas $\mathrm{V}_{1}$. The material belongs to the herpetological collections of the Museum of Comparative Zoology, Harvard University (Cambridge, Massachussetts, U.S.A.; MCZ) and the Museo Nacional de Ciencias Naturales (Madrid, Spain; MNCN). The following species and specimens have been measured or figured (other comparative material studied is not indicated): Calotriton asper (MNCN 13012); Chioglossa 
lusitanica (MNCN 1038); Cynops pyrrhogaster (MNCN 15972); Echinotriton andersoni (MCZ 2579); Euproctus platycephalus (MCZ 2167); Hypselotriton wolsterstorffi $\left(\mathrm{V}_{7}, \mathrm{MCZ} 7173\right)$; Ichthyosaura alpestris (MNCN 16181, 16178); Lissotriton meridionalis (MNCN 18014); Lyciasalamandra luschani (MNCN 23700); Mertensiella caucasica (MNCN 15973); Neurergus sp. (probably $N$. crocatus) (MCZ 24182); Notophthalmus viridescens (MNCN 11838); Ommatotriton vittatus (MNCN 13193); Pachytriton brevipes (MCZ 22345); Paramesotriton hongkongensis (MNCN 23557, MCZ 27094); Pleurodeles waltl (MNCN 16176, 19667); Salamandra salamandra (MNCN 16159, 13262); Salamandrina terdigitata (MNCN 16273, 16279); Taricha granulosa (MNCN 11832, 11830); Triturus marmoratus (MNCN 16067); Tylototriton verrucosus (MNCN 13017, 13016).

\subsection{Phylogenetic inference}

We performed all of the phylogenetic analyses in PAUP*v4.0a123 (Swofford, 1998). We implemented parsimony heuristics searches under the 'Branch \& Bound' option with 'further addition sequences'. We summarized the resulting phylogenetic hypotheses in strict and $50 \%$ majority rule consensus trees. In agreement with the results of Pyron \& Wiens (2011), the genus Salamandrina was specified as outgroup in all of the phylogenetic analyses. We compared distances between trees by means of the 'Symmetric Difference' statistic ('d') (Penny \& Hendy, 1985), as implemented in the 'Tree-to-Tree Distances' option in PAUP*. All of the resulting trees were edited in FigTree v1.3.1 (http://tree.bio.ed.ac.uk/software/figtree/). For general statistical analyses, we used the software PAST (Hammer et al., 2001).

\subsection{Psychological intravertebral conspicuity test design}

An international group of 20 graduate students attending a workshop on Systematic Biology (Erasmus Program ICP96-NL-3041/13, Madrid 1997) were requested to answer questions on a simple image-based test. The participants were interested in systematics and taxonomy, but were not familiar with palaeoherpetology or osteology. The test was intended to measure the relative conspicuity of different vertebral substructures. Schematic outlines of the middle trunk vertebrae of the different salamandrid genera and subgenera were presented in dorsal and lateral views (Figs $1,2)$. We also included an answer sheet with the repeated scheme of a generalised vertebra outline. We asked the participants to detect the parts of the vertebra in which they observed morphological variation among taxa, by order of conspicuity, and to colour them in the answer sheet. An example test answer is shown in Figure 3. Minor nomenclatural changes have occurred in the taxonomy of this family since we performed this test, primarily regarding the upgrading of the former Triturus subgenera to genera. However, they do not affect the results obtained in this study.

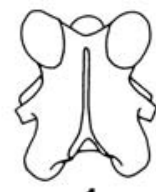

1

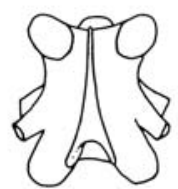

5

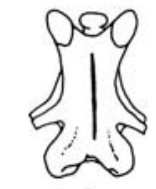

9

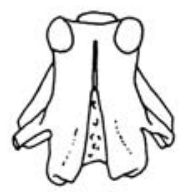

13

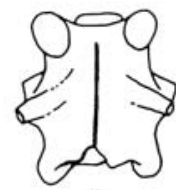

2

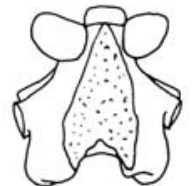

6

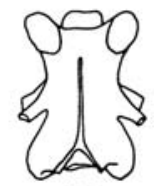

10

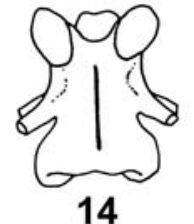

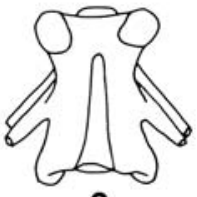

3

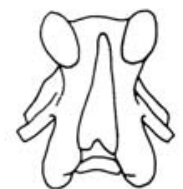

7

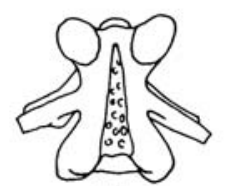

11

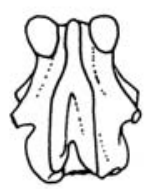

15

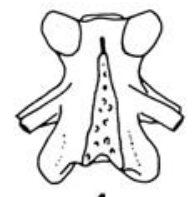

4

8

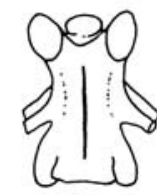

12

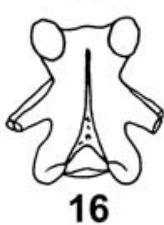

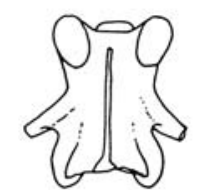

Figure 1. Schematic outline of salamandrid vertebrae in dorsal view. 1: Calotriton; 2: Pleurodeles; 3: Cynops; 4: Tylototriton; 5: Neurergus; 6: Echinotriton; 7: Notophthalmus; 8: Pachytriton; 9: Chioglossa; 10: Triturus; 11: Paramesotriton; 12: Mertensiella; 13: Hypselotriton; 14: Salamandra; 15: Salamandrina; 16: Taricha.

We processed the results of the test in the following way:

1.- For each test, we annotated: 1) The series of vertebral structures identified as discriminant among subsets of taxa, and 2) the relative rank of these structures as more or less conspicuous. For example, in Figure 3, the participant chose the following structures as informative units of variation, and ranked their conspicuity as follow: 1) Neurapophyses, 2) centrum condyle and cotylar height, $e x$ aequo, 3) prezygapophysis, and 4) transverse processes.

2.- The anatomical units selected in each response were paired one to one, annotating which of them was ranked as more conspicuous ("winner"). When the same anatomical structure was selected several times, only its best rank was considered. If the variation was noted by comparison of two structures, both were ranked alike. 


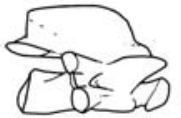

1

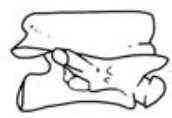

5

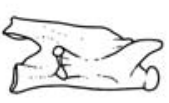

9

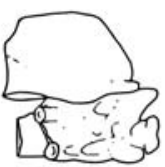

13

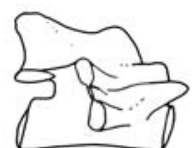

2

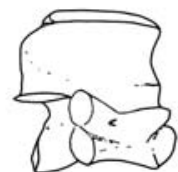

6

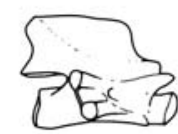

10

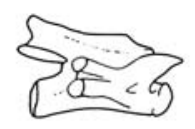

14

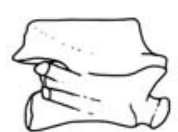

3

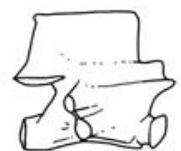

7

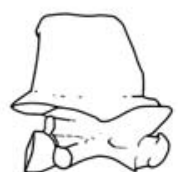

11

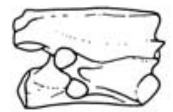

15

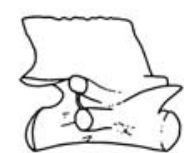

4

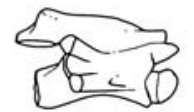

8

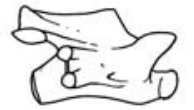

12

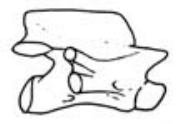

16
Figure 2. Schematic outline of salamandrid vertebrae in lateral view. 1: Calotriton; 2: Pleurodeles; 3: Cynops; 4: Tylototriton; 5: Neurergus; 6: Echinotriton; 7: Notophthalmus; 8: Pachytriton; 9: Chioglossa; 10: Triturus; 11: Paramesotriton; 12: Mertensiella; 13: Hypselotriton; 14: Salamandra; 15: Salamandrina; 16: Taricha.
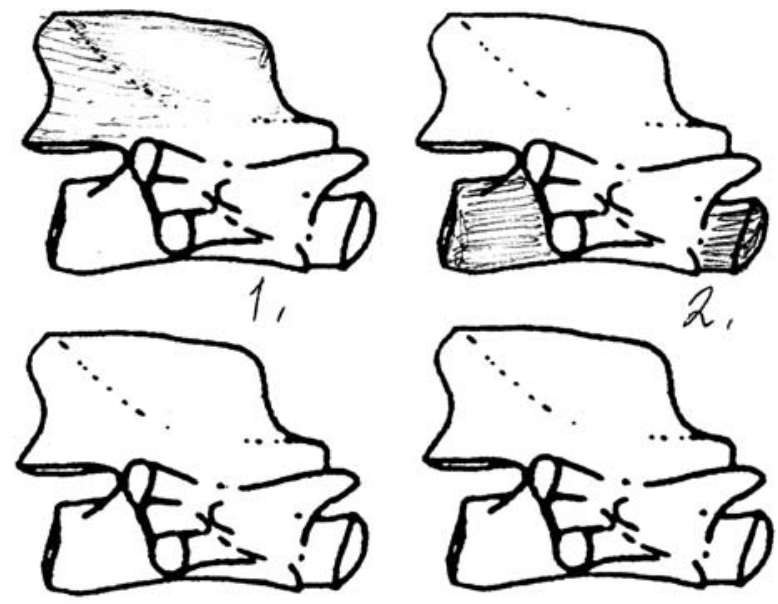

The intravertebral structural conspicuity test was based on the dorsal and lateral view answers. We measured the validity of the test as the correlation of the pairmatches that resulted from lateral and dorsal observations (excluding the centrum, which could not be observed in dorsal view). We assessed the reliability of the test through the correlation of the results from two random subsets of ten answers. Validity and reliability of the test were both statistically significant $(\mathrm{r}=0.88, p<0.001, \mathrm{~N}=42 ; \mathrm{r}=$ $0.79, p<0.001, \mathrm{NB}=56$, respectively).

\subsection{Morphological qualitative characters}

For the selection of morphological characters, we attempted to include most of the traditional features that have been used in the history of the discipline. However, in order to match the conditions of the test described above, we restricted the morphoclines to those that could be observed in dorsal or lateral views. We defined the character states after direct examination of the material. Even though the characters are expected to reflect the accumulated taxonomic tradition of the discipline, we prepared ex novo the morphoclines and character states to avoid the frequent ambiguity and imprecision in the delimitation of the anatomical continuum frequently found in the specialised literature.

The vertebral main orientation axis runs, in lateral view, between the middle of the condyle and cotyle heights and, in dorsal view, between the mid-anterior condyle and cotyle points. Definition of morphoclines and comments are as follow:

Figure 3. Answer sheet of the "conspicuity" test. In this example, the participant chose and ranked the structures in the following order: 1) neurapophyses, 2) centrum condyle and cotylar height, ex aequo, 3) prezygapophysis, 4) transverse processes. 
1.- Bases of neurapophyses reach the anterior border of the neural arch (dorsal view). Character states: (1) yes (Fig. 4A); (2) no (Fig. 4B).
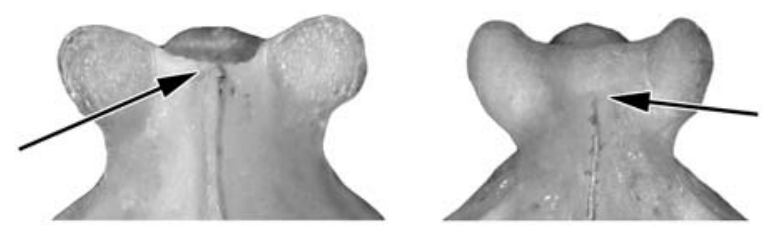

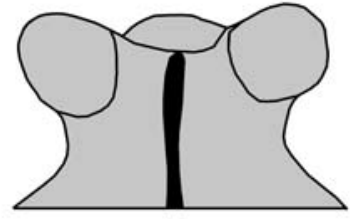

A

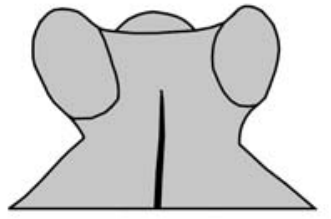

B
Figure 4. Graphic representation of character states for taxonomic character 1 . Bases of neurapophyses reach, the anterior border of the neural arch, in dorsal view. Character states: 1) yes (depicted in A); 2) no (depicted in B).

2.- The width of the neurapophysis in its anterior part is, with relation to its width at the level of a line traced between the ends of the dorsal transverse processes (dorsal view): 1) of similar width (Fig. 5A); 2) much wider posteriorly (Fig. 5B).

3.- Dorsal sculpture on neurapophysis surface (dorsal view): 1) no major irregularities (ornamentation) (Fig. 5A); 2) having clear tubercles or pits (Fig. 5B).

4.- Vertebral imbrication. We consider that there is imbrication when the neurapophysis is clearly present anteriorly to a line tangent to the posterior margin of the prezygapophyseal articular surfaces (dorsal view): 1) imbrication (Fig. 6A); 2) no imbrication (Fig. 6B).

5.- Relative posterior height of neurapophysis with respect to the maximum vertebral length (lateral view): 1) low, index 35 (Fig. 7A); 2) high, index > 35 (Fig. 7B).

6.- Slope of the anterior edge of the neurapophysis with respect to the vertebral orientation axis (lateral view): 1) approximately perpendicular (Fig. 7B); 2) clearly inclined posteriorwards (Fig. 7A).

7.- Orientation of the upper edge of the posterior half of the neurapohysis (lateral view): 1) parallel to the vertebral axis (Figs 8A,C); 2) not parallel to the vertebral axis (Fig. 8B).

8.- Anterior margin of the neural arch. With relation to an imaginary line connecting the centres of the prezygapophyseal articular surfaces, the neural arch notch is placed (dorsal view): 1) anteriorly to the line (Fig. 9A); 2) posteriorly to the line (Fig. 9B).
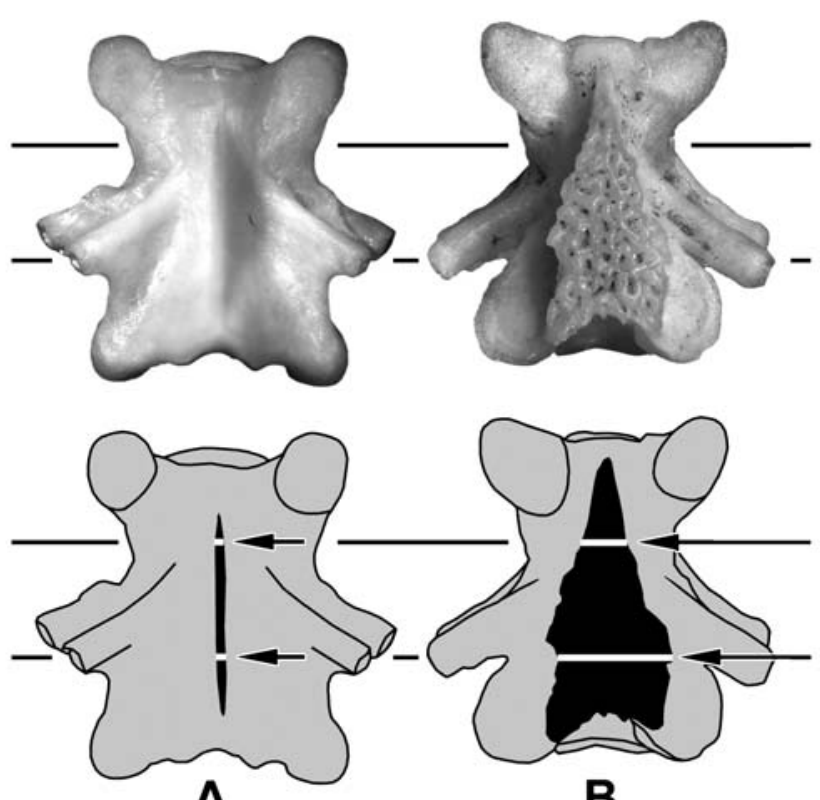

A

B

Figure 5. Graphic representation of character states for taxonomic characters 2 and 3. Character 2: The width of the neurapophysis in its anterior part, with relation to its width at the level of a line traced between the ends of the dorsal transverse processes in dorsal view. Character states: 1) of similar width (depicted in A); 2) much wider posteriorly (depicted in $\mathbf{B}$ ). Character 3: Dorsal sculpture on neurapophysis surface (dorsal view). Character states: 1) no major irregularities (ornamentation) (depicted in $\mathbf{A}$ ); 2) having clear tubercles or pits (depicted in $\mathbf{B}$ ).

9.- Intervertebral articulation type zygosphenezyganthrum (Sanchiz, 1988) (anterior and posterior views): 1) present; 2) absent.

10.- Rib connecting surfaces on upper and lower transverse processes (lateral view): 1) similar (Fig. 10A); 2) clearly dissimilar (Fig. 10B).

11.- Dorsal lateral crests. Their posterior end (lateral view): 1) reaches the dorsal transverse process (Fig. 8A); 2 ) ends between dorsal and ventral transverse processes (Fig. 8B); 3) ends above the dorsal transverse process (Fig. 8C).

12.- Lateral edge of the connection between dorsal and ventral transverse processes: 1) notch present (Fig. 7A); 2) notch absent (Fig. 7B).

13.- Transverse processes protrude with respect to an imaginary line between the lateral edges of the zygapophyses (dorsal view): 1) very little (less than 16.5 $\%$ of the maximum inter pre- or postzygapophyseal width) (Fig. 11A); 2) intermediate, index between 16.5 and 22.5 $\%$ (Fig. 11B); 3) very much, index $>22.5 \%$ (Fig. 11C).

14.- Curvature of the ventral margin of centrum (lateral view): 1) slightly concave, the curvature does not reach 

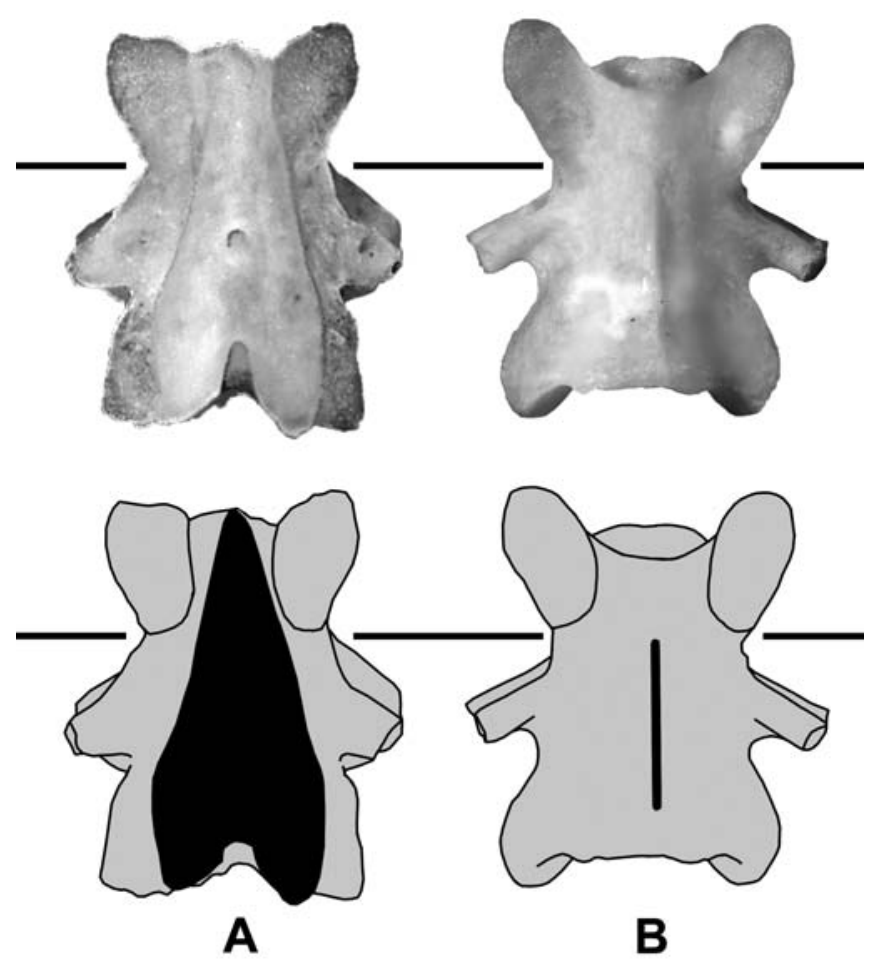

Figure 6. Graphic representation of character states for taxonomic character 4. Vertebral imbrication. We consider that there is imbrication when the neurapophysis is clearly present anterior to a line tangent to the posterior margin of the prezygapophyseal articular surfaces in dorsal view: 1) imbrication (depicted in $\mathbf{A}$ ); 2) no imbrication (depicted in $\mathbf{B}$ ).

half of the cotylar height (Fig. 7B); 2) clearly concave, the curvature reaches or exceeds half the cotylar height (Fig. 7A).

The distribution of character states among taxa is shown in Table 1. The selection of characters and, more importantly, the delimitation of character states, is a function of the taxa set in which they will operate, or its "taxonomic realm". Characters and morphoclines will likely vary if the taxonomic collective changes. As a consequence, the character list given below is not to be considered as a standard proposal. Furthermore, the character set used here is not intended to infer the phylogenetic relationships within Salamandridae as we have a priori assumed that the molecular inference by Pyron \& Wiens (2011) is correct. In addition, we have restricted the characters to those that could be clearly seen in dorsal or lateral silhouettes, and thus, the number of characters is not balanced with respect to the number of operational taxonomic units (OTUs) (14 characters, 1 parsimony-noninformative).
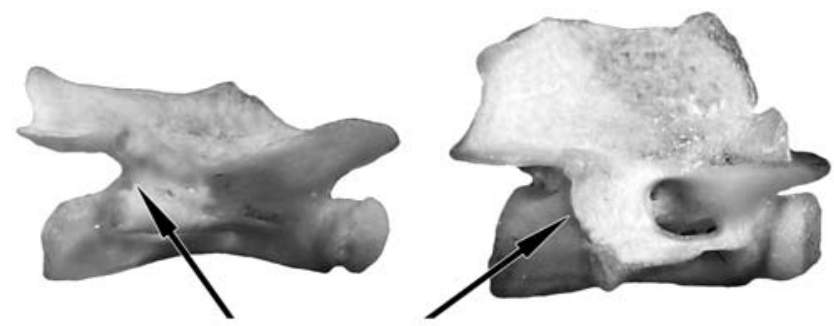

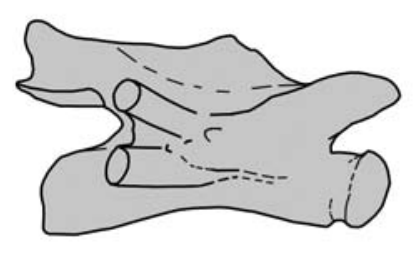

A

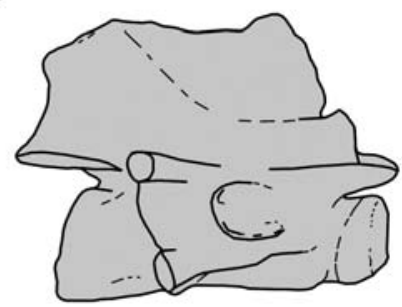

B
Figure 7. Graphic representation of character states for taxonomic characters 5, 6, 12, and 14. Character 5: Relative posterior height of neurapophysis with respect to the maximum vertebral length (lateral view). Character states: 1) low, index 35 (depicted in A); 2) high, index $>35$ (depicted in B). Character 6: Slope of the anterior edge of the neurapophysis with respect to the vertebral orientation axis (lateral view). Character states: 1) approximately perpendicular (depicted in B); 2) clearly inclined posteriorwards (depicted in A). Character 12: Lateral edge of the connection between dorsal and ventral transverse processes. Character states (arrows): 1) notch present (depicted in A); 2) notch absent (depicted in B). Character 14: Curvature of the ventral margin of centrum (lateral view). Character states: 1) slightly concave, the curvature does not reach half of the cotylar height (depicted in B); 2) clearly concave, the curvature reaches or exceeds half the cotylar height (depicted in A).

\section{RESULTS AND DISCUSSION}

Defining characters and morphoclines is, no doubt, the most important step in any phylogenetic study. Much has been written about what constitutes a 'character' from a theoretical and practical point of view and how characters should be defined and coded (e.g., Wagner, 2001; Brazeau, 2011). Most of the taxonomic and systematic studies, however, rely on previously established character matrices, not paying attention to whether the characters used are $a$ priori relevant or significant from a phylogenetic point of view for the taxonomic group under study. In general, there have been few attempts to standardize morphological characters and to analyse their phylogenetic signal and utility, which is remarkable given (i) the importance of character definition and coding for an accurate phylogenetic inference and (ii) the relative subjectivity of the process of defining characters. To roughly approximate 

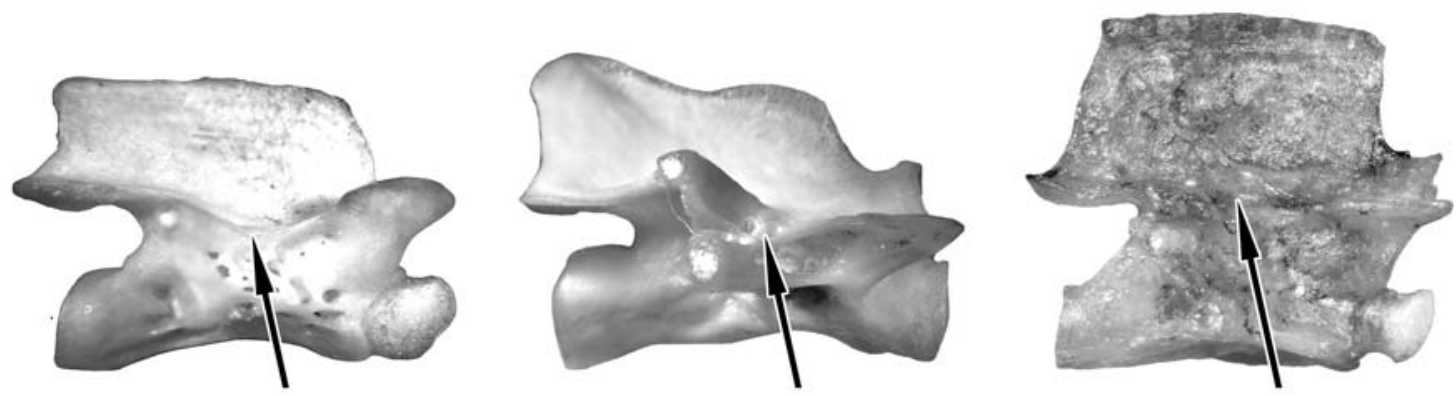

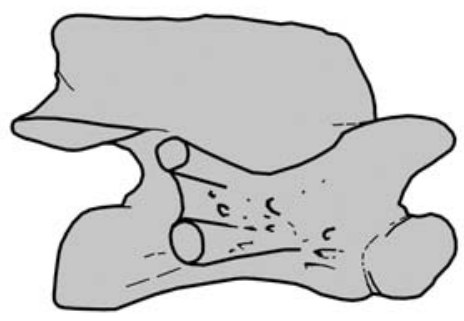

A

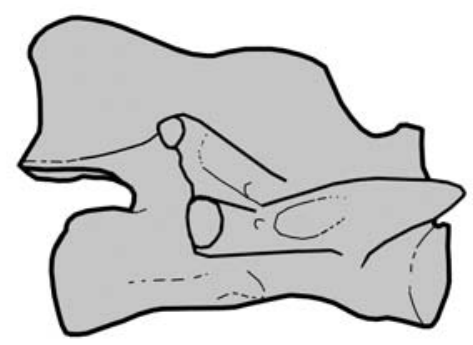

B

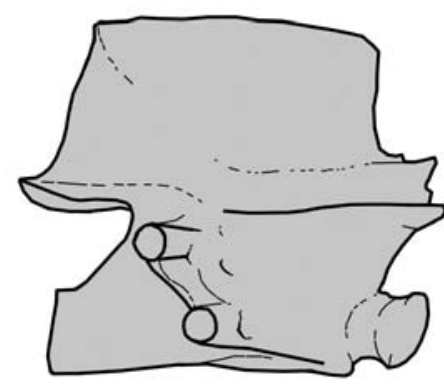

C

Figure 8. Graphic representation of character states for taxonomic characters 7 and 11. Character 7: Orientation of the upper edge of the posterior half of the neurapohysis (lateral view). Character states: 1) parallel to the vertebral axis (depicted in $\mathbf{A}$, C); 2) not parallel to the vertebral axis (depicted in B). Character 11: Posterior end of the dorsal lateral crests (arrows). Character states: 1) reaches the dorsal transverse process (depicted in A); 2) ends between dorsal and ventral transverse processes (depicted in $\mathbf{B}$ ); 3) ends above the dorsal transverse process (depicted in $\mathbf{C}$ ).
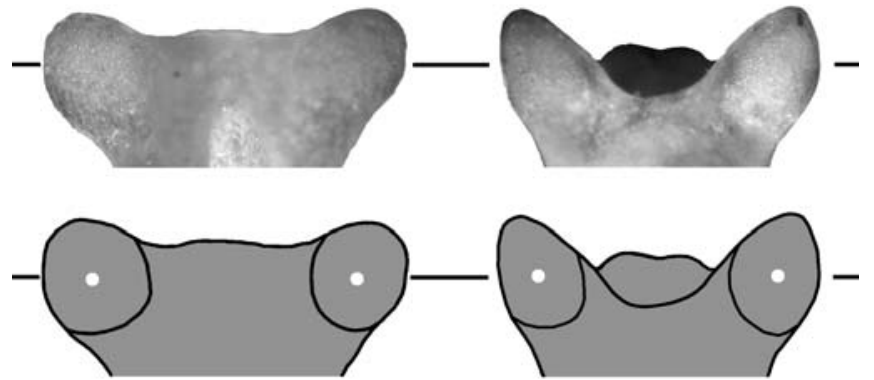

A

B

Figure 9. Graphic representation of character states for taxonomic character 8. Anterior margin of the neural arch. With relation to an imaginary line connecting the centres of the prezygapophyseal articular surfaces, the neural arch notch is placed (dorsal view): 1) anteriorly to the line (depicted in $\mathbf{A}$ ); 2) posteriorly to the line (depicted in B).
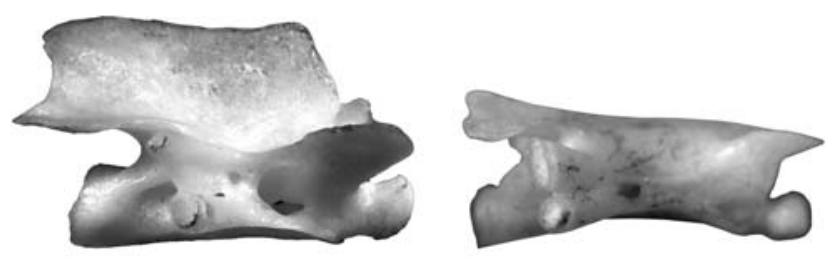

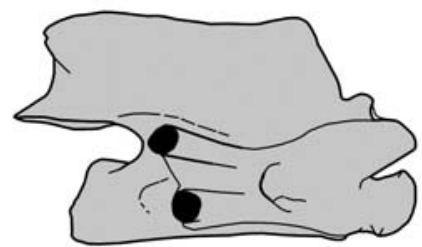

A

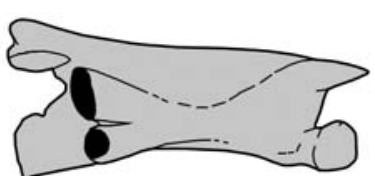

B
Figure 10.Graphic representation of character states for taxonomic character 10. Rib connecting surfaces on upper and lower transverse processes (lateral view). Character states: 1) similar (depicted in A); 2) clearly dissimilar (depicted in B). 

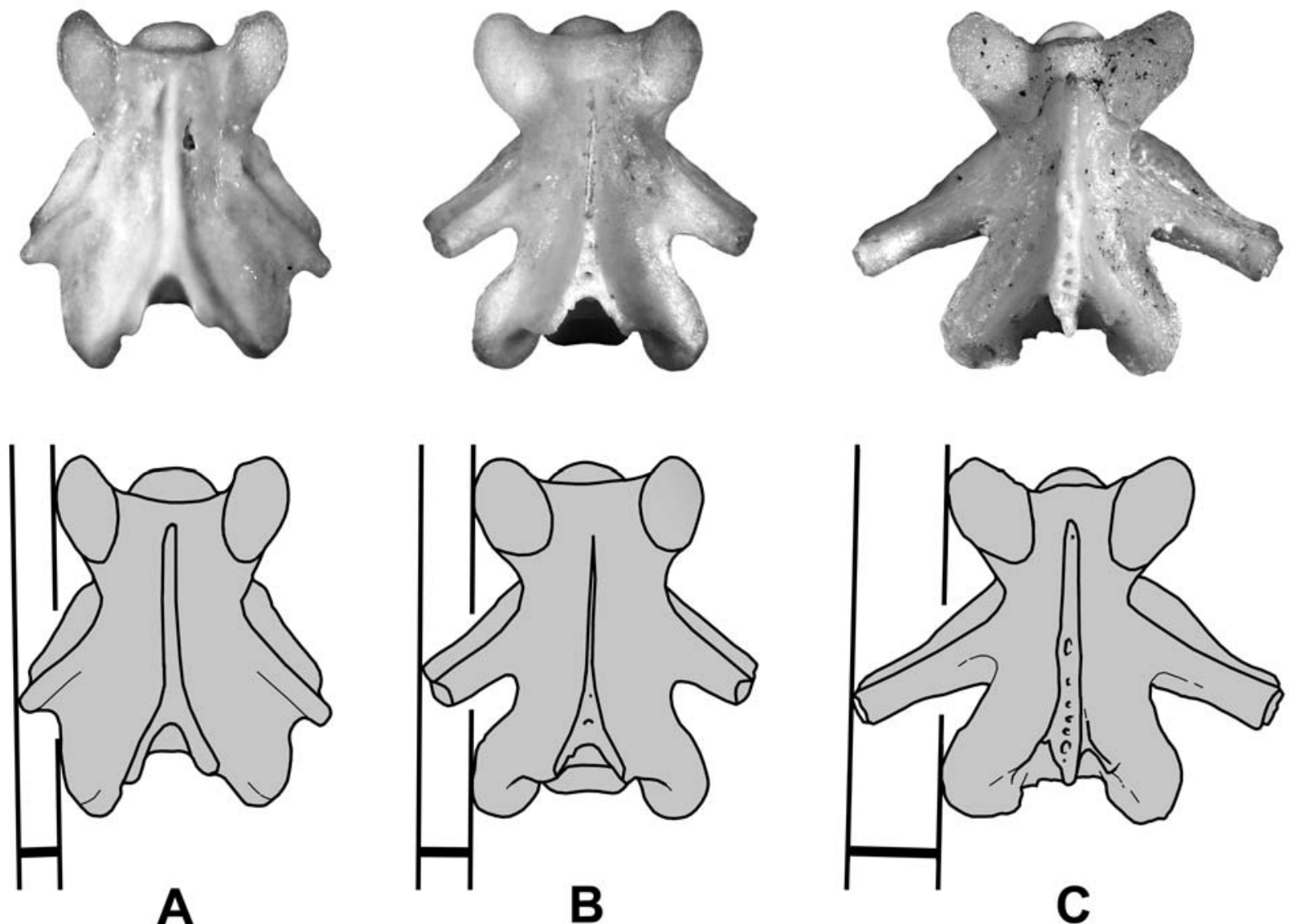

Figure 11. Graphic representation of character states for taxonomic character 13. Transverse processes protrude with respect to an imaginary line between the lateral edges of the zygapophyses (dorsal view). Character states: 1) very little (less than 16.5 $\%$ of the maximum inter pre- or postzygapophyseal width) (depicted in A); 2) intermediate, index between 16.5 and 22.5 $\%$ (depicted in B); 3) very much, index $>22.5 \%$ (depicted in $\mathbf{C})$.

the importance of this issue, we designed a psychological test to analyse the relevance of conspicuity as a factor for delimiting and choosing characters. The test was designed using a data set of vertebrae from all the genera within Salamandridae.

The results of the individual responses to the conspicuity test are shown in Table 2, and the pairings of characters for the whole sample are summarized in Table 3. As clearly shown in Table 2, some vertebral structures were selected more often than others: for instance, $100 \%$ of the participants selected the neurapophyses as a relevant character, while the neural arch was only selected in $25 \%$ of the tests. A similar level of disparity was observed in the paired confrontations. For instance, the neurapophysis $v s$. prezygapophyses pairing resulted in a 16 to 1 score, that is, in the 17 tests in which both structures were selected, on only one occasion was the variation related to the prezygapophysis considered more conspicuous than the one related to the neurapophysis (Table 3 ).

The preference scores for each anatomical vertebral substructure (Table 3) were calculated as: 1) the ratio of the number of times a structure was chosen as more conspicuous to the total matches (W/T), and 2) as the ratio of the mean wins over losses for all of the different pairings $(\mathrm{W} / \mathrm{L})$. These results can be taken as a measure of the conspicuity of each anatomical part, which we expect is derived from basic shape recognition capabilities in this inexpert group. We then used the W/T scores as a weighting factor for characters in the phylogenetic analyses.

As previously mentioned, we accept the salamandrid phylogenetic relationships proposed by Pyron \& Wiens (2011) as the best current inference (Fig. 12A). Having this standard model for comparison, it becomes possible to assess differences between the phylogenetic inferences derived from the character set used by traditional palaeobatrachologists (specialists) and the character set modified through the character-weighting scheme.

Using the traditional characters without any weighting and the search parameters indicated, we obtained 315 equally most parsimonious trees (42 steps, Consistency Index $\mathrm{CI}=0.381$; Retention Index $\mathrm{RI}=0.671)$. The 'Symmetric Different' statistic ('d') between the 'Strict' 
Table 1. Distribution of qualitative taxonomic character states. See the text for a complete description of the characters and character states.

\begin{tabular}{ccccccccccccccc}
\hline Taxa/Character & $\mathbf{1}$ & $\mathbf{2}$ & $\mathbf{3}$ & $\mathbf{4}$ & $\mathbf{5}$ & $\mathbf{6}$ & $\mathbf{7}$ & $\mathbf{8}$ & $\mathbf{9}$ & $\mathbf{1 0}$ & $\mathbf{1 1}$ & $\mathbf{1 2}$ & $\mathbf{1 3}$ & $\mathbf{1 4}$ \\
\hline Calotriton & 2 & 1 & 1 & 1 & 2 & 2 & 2 & 2 & 2 & 1 & 1 & 2 & 1 & 1 \\
Chioglossa & 2 & 1 & 1 & 2 & 1 & 2 & 2 & 2 & 2 & 2 & 2 & 1 & 1 & 1 \\
Cynops & 2 & 2 & 2 & 2 & 1 & 1 & 1 & 1 & 2 & 1 & 1 & 2 & 3 & 1 \\
Echinotriton & 1 & 2 & 2 & 1 & 2 & 1 & 1 & 1 & 2 & 1 & 1 & 2 & 1 & 2 \\
Euproctus & 2 & 1 & 1 & 1 & 1 & 2 & 1 & 2 & 2 & 1 & 1 & 2 & 1 & 2 \\
Hypselotriton & 2 & 2 & 2 & 1 & 2 & 2 & 1 & 1 & 2 & 2 & 3 & 2 & 3 & $?$ \\
Ichthyosaura & 2 & 1 & 1 & 1 & 1 & 2 & 1 & 1 & 2 & 2 & 1 & 2 & 2 & 2 \\
Lissotriton & 2 & 1 & 1 & 2 & 1 & 2 & 1 & 1 & 2 & 2 & 2 & 2 & 1 & 2 \\
Lyciasalamandra & 2 & 1 & 1 & 2 & 1 & 2 & 2 & 2 & 2 & 1 & 1 & 1 & 1 & 2 \\
Mertensiella & 2 & 1 & 1 & 2 & 1 & 2 & 1 & 2 & 2 & 1 & 2 & 1 & 1 & 1 \\
Neurergus & 1 & 2 & 2 & 1 & 1 & 2 & 1 & 1 & 2 & 1 & 1 & 2 & 1 & 1 \\
Notophthalmus & 2 & 2 & 2 & 1 & 2 & 1 & 1 & 1 & 2 & 1 & 3 & 2 & 2 & 1 \\
Ommatotriton & 2 & 1 & 1 & 1 & 1 & 1 & 1 & 1 & 2 & 1 & 1 & 2 & 2 & 2 \\
Pachytriton & 2 & 1 & 1 & 1 & 1 & 2 & 2 & 1 & 2 & 1 & 1 & 2 & 2 & 2 \\
Paramesotriton & 2 & 2 & 2 & 1 & 2 & 1 & 1 & 1 & 2 & 1 & 2 & 2 & 3 & 2 \\
Pleurodeles & 2 & 1 & 1 & 2 & 2 & 2 & 2 & 1 & 2 & 1 & 2 & 2 & 1 & 2 \\
Salamandra & 2 & 1 & 1 & 2 & 1 & 2 & 2 & 2 & 2 & 2 & 1 & 1 & 1 & 1 \\
Salamandrina & 1 & 2 & 2 & 1 & 1 & 1 & 1 & 1 & 1 & 1 & 1 & 2 & 1 & 1 \\
Taricha & 2 & 2 & 2 & 2 & 1 & 1 & 1 & 1 & 2 & 2 & 1 & 2 & 2 & 2 \\
Triturus & 2 & 1 & 1 & 2 & 2 & 1 & 1 & 1 & 2 & 1 & 1 & 2 & 1 & 2 \\
Tylototriton & 2 & 2 & 2 & 1 & 2 & 1 & 1 & 1 & 2 & 1 & 2 & 2 & 2 & 2 \\
\hline & & & & & &
\end{tabular}

and ' $50 \%$ Majority Rule' consensus trees, and the Pyron $\&$ Wiens phylogeny were 23 and 29, respectively (Fig. 12 , Table 4). When weighting the characters based on the conspicuity test, we obtained 84 most parsimonious trees (30.89 steps, Consistency Index CI=0.385; Retention Index $\mathrm{RI}=0.698$ ); their consensus differed by $\mathrm{d}=27$ (Strict) and $\mathrm{d}=29$ (50\% Majority Rule) from the model designated for comparison. Despite the different weighting factors among characters, the differences between trees derived from the specialists and inexpert matrices were very small ( $d=22$ to 27 for Strict Consensus; Fig. 12) or non-existent (d=29-30 for $50 \%$ Majority Rule; Fig. 12, Table 4).

The results observed in this study indicate that traditional palaeoherpetologists have strongly relied on morphological conspicuity for descriptions and diagnostic traits. As most of these characters are historically based on single vertebral substructures, this conclusion was not completely unexpected. In other words, vertebral characters used in palaeoherpetology essentially describe the variability in single structures within vertebrae observed among different groups. The observed variability is thus concomitant with perception capacities. These capacities
Table 2. Results from the 'conspicuity' tests. The relevance of each vertebral structure (conspicuity) is ranked from 1 to $\mathrm{n}$, with 1 being the most conspicuous and, thus, the most relevant structure for comparative purposes, according to each participant. Abbreviations of vertebral structures are as follows: Neur.= Neurapophysis; Cond. $=$ Condyle; Coty. $=$ Cotyle; Centr. $=$ Centrum; Arch $=$ Neural arch; Tr.Pr. $=$ Transverse processes; Prezy. = Prezygapophysis; Postzy. = Postzygapophysis; * = structure not mentioned by the participant.

\begin{tabular}{|c|c|c|c|c|c|c|c|c|}
\hline & Neur. & Cond. & Coty. & Centr. & Arch & Tr.Pr. & Prezy. & Postzy. \\
\hline 1 & 1 & $*$ & 5 & 4 & $*$ & 2 & 3 & 6 \\
\hline 2 & 1 & 1 & 2 & $*$ & $*$ & 2 & 3 & $*$ \\
\hline 3 & 1 & 3 & $*$ & $*$ & 2 & $*$ & 4 & $*$ \\
\hline 4 & 1 & 5 & 3 & 3 & $*$ & 2 & 4 & $*$ \\
\hline 5 & 1 & 5 & 3 & 2 & 1 & 2 & 6 & 4 \\
\hline 6 & 1 & 3 & $*$ & 2 & $*$ & 4 & 2 & $*$ \\
\hline 7 & 1 & $*$ & $*$ & 2 & 1 & 3 & 4 & 2 \\
\hline 8 & 1 & $*$ & $*$ & 2 & $*$ & 3 & 4 & 2 \\
\hline 9 & 4 & $*$ & $*$ & 2 & 3 & 1 & 5 & $*$ \\
\hline 10 & 1 & 2 & 2 & 2 & $*$ & 4 & 3 & * \\
\hline 11 & 1 & 2 & $*$ & $*$ & $*$ & 3 & 4 & 5 \\
\hline 12 & 1 & $*$ & 3 & 3 & 5 & 2 & 4 & $*$ \\
\hline 13 & 1 & $*$ & $*$ & 2 & 1 & 2 & 3 & $*$ \\
\hline 14 & 2 & 3 & $*$ & 1 & $*$ & 1 & 1 & 4 \\
\hline 15 & 1 & 2 & $*$ & * & * & 3 & $*$ & $*$ \\
\hline 16 & 1 & 3 & 2 & * & 7 & 5 & 6 & 4 \\
\hline 17 & 1 & 2 & 5 & 3 & 1 & 4 & 7 & 6 \\
\hline 18 & 1 & 2 & $*$ & $*$ & 1 & 2 & 3 & 4 \\
\hline 19 & 1 & 4 & $*$ & 5 & 3 & 2 & 3 & 6 \\
\hline 20 & 1 & 2 & 1 & 1 & 1 & 1 & 1 & 1 \\
\hline
\end{tabular}

are likely more developed within the specialist community and, as such, expert palaeoherpetologists would be able to define variations among groups more precisely, but are, nevertheless, inherent to human capacities (as shown by the untrained participant results). Despite the importance of character definition and description, it is paradoxical that more sophisticated possibilities of character building have not been explored in palaeoherpetology. For instance, the definition of characters based on the relationship among substructures has seldom been explored. This, together with the possibilities offered by modern analytical and visual tools (e.g., X-ray based Computer Tomography) and new approaches, such as in developmental biology, would provide new resources for defining novel quantitative and qualitative characters. More importantly, explicit analyses on the foundations of systematic morphological characters 


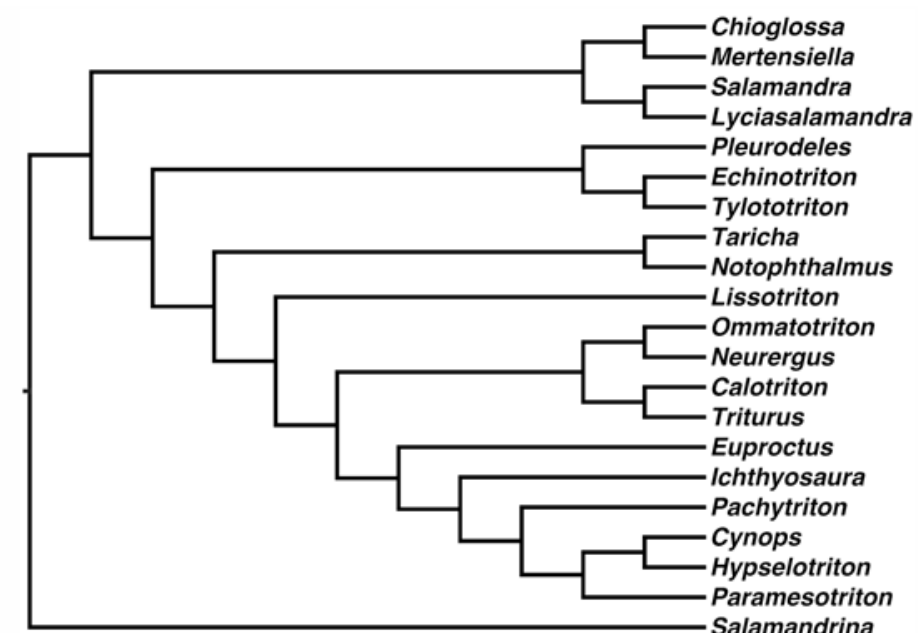

A

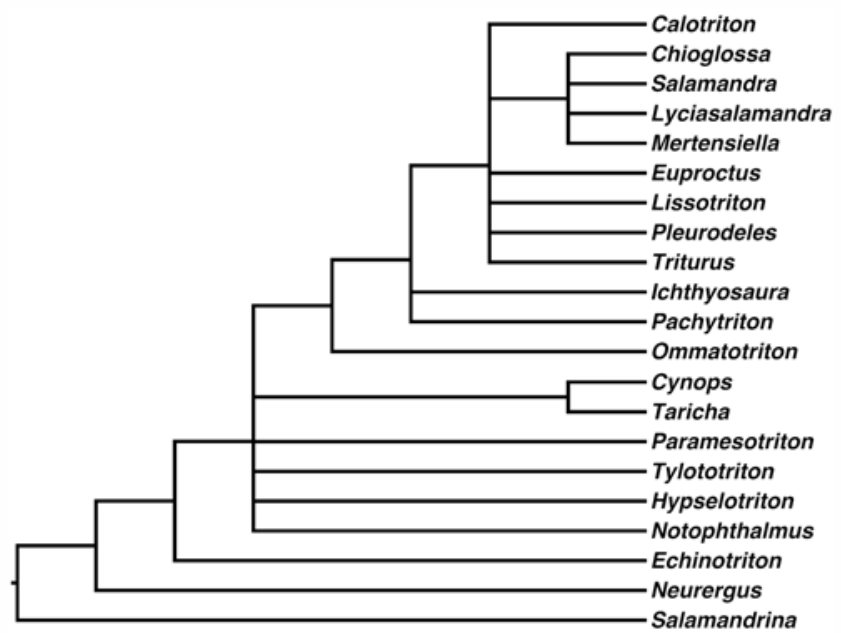

B

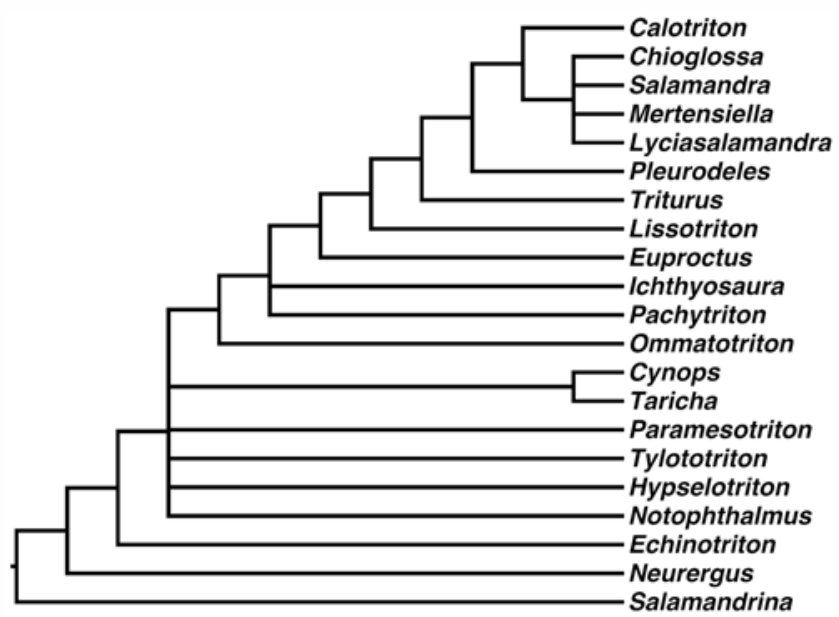

D

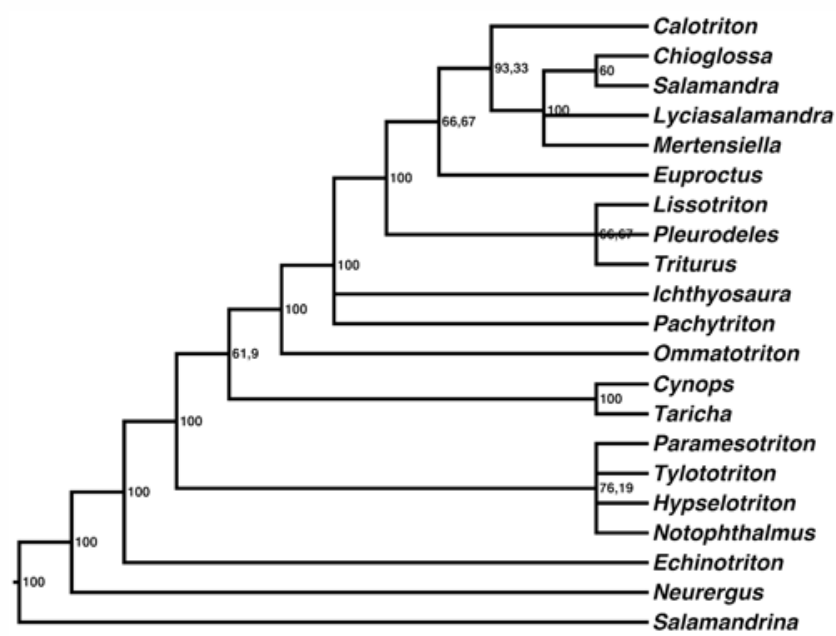

C

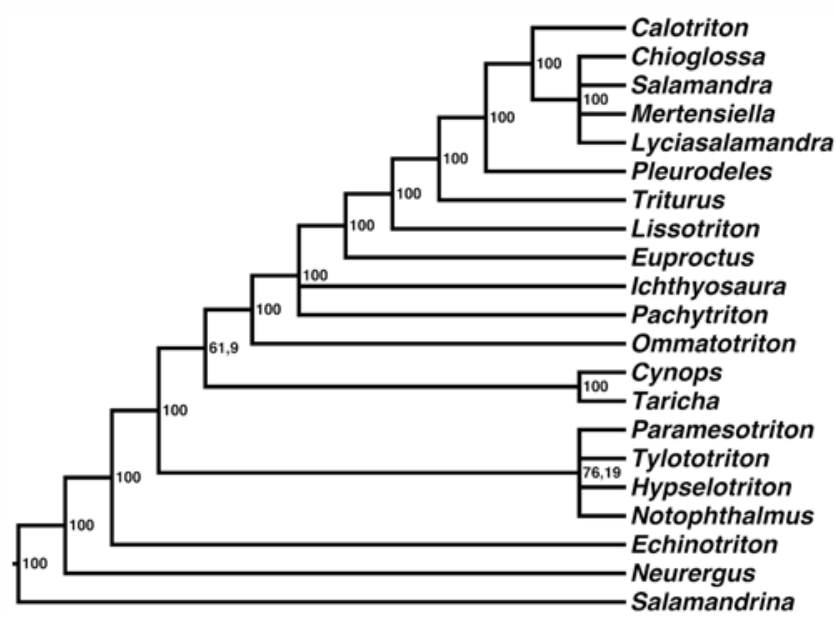

E

Figure 12. Phylogenetic Analyses. Strict and $50 \%$ Majority Rule consensus trees of the phylogenetic hypotheses reconstructed from the morphological matrix in Table 1. (A) A phylogenetic hypothesis based on mitochondrial and nuclear data is compared to consensus topologies that are not using (B, Strict Consensus, and C, $50 \%$ Majority Rule) or using (D, Strict Consensus, and $\mathbf{E}, 50 \%$ Majority Rule) the character weighting scheme derived from the 'conspicuity' test. 
Table 3. Matches among vertebral structure pairs. The pairing scores between vertebrate structures are summarized. Each cell in the table shows how many times a vertebral structure (rows) was ranked as more conspicuous that another vertebral structure (columns) among the 20 tests scored. For instance, neurapophysis and transverse processes were selected in 19 tests. Among those, neurapophysis 'won' (was ranked as more conspicuous) 17 times, while the tranverse processes 'won' only 2 times. Abbreviations of vertebral structures are as follows: Neur. $=$ Neurapophysis; Cond. $=$ Condyle; Coty. $=$ Cotyle; Centr. $=$ Centrum; Arch $=$ Neural arch; Tr.Pr. $=$ Transverse processes; Prezy. = Prezygapophysis; Postzy. = Postzygapophysis; W/L: ratio of mean wins to losses of a vertebral structure; W/T: ratio of wins to the total pairing events a vertebral structure. This ratio was used to weight the characters in the phylogenetic analyses.

Neur. Cond. Coty. Centr. Arch Tr.Pr. Prezy. Postzy. W/L W/T

\begin{tabular}{ccccccccccc}
\hline Neur. & $*$ & 19 & 19 & 17 & 12 & 17 & 18 & 19 & 20,17 & 0,95 \\
Cond. & 0 & $*$ & 9 & 8 & 7 & 8 & 9 & 12 & 0,73 & 0,42 \\
Coty. & 0 & 6 & $*$ & 2 & 6 & 2 & 7 & 8 & 0,4 & 0,28 \\
Centr. & 2 & 11 & 10 & $*$ & 7 & 5 & 9 & 11 & 1 & 0,5 \\
Arch & 1 & 10 & 8 & 8 & $*$ & 6 & 7 & 9 & 0,86 & 0,46 \\
Tr.Pr. & 2 & 11 & 15 & 10 & 12 & $*$ & 15 & 15 & 1,81 & 0,64 \\
Prezy. & 1 & 11 & 11 & 7 & 9 & 3 & $*$ & 13 & 0,78 & 0,44 \\
Postzy. & 0 & 5 & 6 & 3 & 4 & 3 & 5 & $*$ & 0,3 & 0,23 \\
\hline
\end{tabular}

Table 4. "Symmetric Difference" statistic (Penny \& Hendy, $1985)$ between trees. Pyron \& Wiens $=$ molecular tree based on Pyron \& Wiens (2011). Strict = Strict consensus tree generated from the morphological matrix (Table 1); $\mathbf{M J 5 0 \%}=50 \%$ Majority Rule consensus tree generated from the morphological matrix (Table 1); Strict_weighted $=$ Strict consensus tree after applying the weight scheme from the "conspicuity test"; MJ50\%_weighted = 50\% Majority Rule consensus tree after applying the weight scheme from the "conspicuity test".

\begin{tabular}{c|ccccc}
\hline tree & $\begin{array}{c}\text { Pyron \& } \\
\text { Wiens }\end{array}$ & Strict & MJ50\% & $\begin{array}{c}\text { Strict__ } \\
\text { weighted }\end{array}$ & $\begin{array}{c}\text { MJ50\%_ } \\
\text { weighted }\end{array}$ \\
\hline Pyron \& Wiens & 0 & & & & \\
Strict & 23 & 0 & & & \\
MJ50\% & 29 & 6 & 0 & & \\
Strict_weighted & 27 & 4 & 8 & 0 & \\
MJ50\%_weighted & 29 & 6 & 6 & 2 & 0 \\
\hline
\end{tabular}

are strongly required. The development of explicit standardization and systematic analyses of character utility, together with the development of novel quantitative and qualitative characters is, in our opinion, the best way to acquire valid and reliable tools for future palaeontological research.

\section{ACKNOWLEDGEMENTS}

This research was presented in a workshop (Miraflores, March 2012) honouring the late Prof. Nieves López Martínez, with whom we have had the privilege of discussing problems related to the character concept, and to whom we will always be grateful. The collection of the Museum of Comparative Zoology was initially examined thanks to an E. Mayr 1987 travel grant. We thank J. Rosado and J.E. González for their assistance with the herpetological collections in their care. F.M. Buzzetti and S. Celotto were participants and collaborators in the 1997 workshop test, and used it for their training in compatibility analyses. Carolina Martín was involved in the preparation of figures and assisted our study in many other ways. We also thank Melinda Modrell for her comments on the manuscript, and Massimo Delfino and one anonymous reviewer for their helpful revisions that have certainly improved the final text. Research was supported by the Spanish Government grant CGL2011-28877 to BS. DB was supported by a JAE-DOC fellowship from the CSIC, under the program "Junta para la Ampliación de Estudios" co-financed by the European Social Fund (ESF).

\section{REFERENCES}

Brazeau, M.D. 2011. Problematic character coding methods in morphology and their effects. Biological Journal of the Linnean Society, 104, 489-498.

Estes, R. 1982. Systematics and paleogeography of some fossil salamanders and frogs. Research Reports of the National Geographic Society, 14, 191-210.

Frost, D.R. 2011. Amphibian Species of the World: an Online Reference. Version 5.5 (31 January, 2011). Electronic Database accessible at http://research.amnh.org/vz/ herpetology/amphibia/ American Museum of Natural History, New York, USA.

Haller-Probst, M. \& Schleich, H.H. 1994. Vergleichende osteologische Untersuchungen an einigen Urodelen Eurasiens (Amphibia: Urodela, Salamandridae, Proteidae). Courier Forschungsinstitut Senckenberg, 173, 23-77.

Hammer, Ø., Harper, D.A.T. \& Ryan, P.D. 2001. PAST: Paleontological statistics software package for education and data analysis. Palaeontologia Electronica, 4, 9.

Martín, C. \& Sanchiz, B. 2012. Lisanfos KMS. Version 1.2. Online reference accessible at http://www.lisanfos.mncn. 
csic.es/. Museo Nacional de Ciencias Naturales, MNCNCSIC. Madrid, Spain.

Milner, A.R. 2000. Mesozoic and Tertiary Caudata and Albanerpetontidae. In: Amphibian Biology. Volume 4. Palaeontology. The Evolutionary History of Amphibians. (eds. Heatwole, H. \& Carroll, R.L.), Surrey Beatty, Chipping Norton, Australia, i-x, 1412-1444.

Naylor, B. 1978. The systematic of fossil and recent salamanders (Amphibia: Caudata), with special reference to the vertebral column and trunk musculature. $\mathrm{PhD}$ Thesis, University of Alberta, Canada (unpublished).

Penny, D. \& Hendy, M.D. 1985. The use of tree comparison metrics. Systematic Zoology, 34, 75-82.

Pyron, R.A. \& Wiens, J.J. 2011. A large-scale phylogeny of Amphibia including over 2800 species, and a revised classification of extant frogs, salamanders, and caecilians. Molecular Phylogenetics and Evolution, 61, 543-583.

Sanchiz, B. 1988. On the presence of zygosphene-zygantrum vertebral articulations in Salamandrids. Acta Zoologica Cracoviensia, 31, 493-504.

Swofford, D.L. 1998. PAUP*: Phylogenetic Analysis Using parsimony (*and other Methods). Version 4.0a123. Sinauer Associates, Sunderland, Massachusetts.

Teege, M.J. 1957. Studien zur Entwicklung und Gestalt der Urodelenwirbel. Zeitschrift für Wissenschaftliche Zoologie, 160, 95-163.

Wagner, G.P. (ed.). 2001. The Character Concept in Evolutionary Biology. Academic Press, San Diego.

Worthington, R.D. \& Wake, D.B. 1972. Patterns of regional variation in the vertebral column of terrestrial salamanders. Journal of Morphology, 137, 257-277. 